\title{
LMNA is mutated in Hutchinson-Gilford progeria (MIM 176670) but not in Wiedemann-Rautenstrauch progeroid syndrome (MIM 264090)
}

Received: 11 March 2003/ Accepted: 13 March 2003/Published online: 3 April 2003

(C) The Japan Society of Human Genetics and Springer-Verlag 2003

\begin{abstract}
Hutchinson-Gilford progeria syndrome (HGPS; MIM 176670) is an extremely rare disease that is characterized by accelerated aging and early death, frequently from coronary artery disease. WiedemannRautenstrauch syndrome (WRS; MIM 264090) is another extremely rare disease that is characterized by progeroid features from birth with multiple somatic anomalies and paucity of subcutaneous fat. Because mutations in $L M N A$, encoding nuclear lamin $\mathrm{A} / \mathrm{C}$, cause other lipodystrophy syndromes, we sequenced LMNA (MIM 150330) from the genomic DNAs of seven unrelated HGPS probands and two unrelated WRS probands. We found four novel LMNA coding sequence variants among the HGPS probands, namely R471C, R527C, G608S and c.2036C > T. All seven HGPS probands had at least one $L M N A$ variant, which were found in none of the genomes of 100 normal subjects $\left(P<4 \times 10^{-11}\right)$. In contrast, neither of the WRS proband genomes had any $L M N A$ sequence abnormality. The strong association of rare $L M N A$ coding sequence mutations with HGPS implicates this syndrome as a laminopathy, while WRS is most probably due to mutations in another gene.
\end{abstract}

Keywords Progeria - Atherosclerosis . Lipodystrophy $\cdot$ Genomic DNA · Sequencing · Monogenic disease

\section{Introduction}

The Hutchinson-Gilford progeria syndrome (HGPS; MIM 176670) has existed as a named clinical entity

H. Cao · R. A. Hegele $(\bowtie)$

Blackburn Cardiovascular Genetics Laboratory,

Robarts Research Institute, 406-100 Perth Drive,

London, Ontario, N6A 5K8, Canada

E-mail: hegele@robarts.ca

Tel.: + 1-519-6633461

Fax: + 1-519-6633037 for almost 100 years (Hutchinson 1886; Gilford 1904). Organ systems degenerate to such an extent that the affected subject resembles an old person. Clinical features include short stature, micrognathia, alopecia, prominent scalp veins, prominent joints, hyperlipidemia and atherosclerosis, often with premature death from coronary artery disease (de Paula Rodrigues et al. 2002). HGPS was proposed to have autosomal recessive inheritance (Gabr et al. 1960), but other mechanisms, such as chromosomal rearrangements or uniparental disomy, appear to be important in some instances (Brown et al. 1990; Luengo et al. 2002; Eriksson et al. 2002). No mutations have yet been reported in affected subjects, but there are clues to the molecular genetic basis of HGPS. For instance, HGPS patients can have an absence of subcutaneous fat reminiscent of lipodystrophy (Paterson 1922). In some HGPS patients (Parkash et al. 1990) the clinical presentation resembled mandibuloacral dysplasia with partial lipodystrophy (MIM 248370), which is caused by mutant $L M N A$, encoding nuclear lamin $\mathrm{A} / \mathrm{C}$ on chromosome 1q21 (Novelli et al. 2002). Also, some HGPS patients had an inverted insertion of 1q (Brown et al. 1990) and another had an interstitial deletion involving 1q23 (Luegno et al. 2002). Yet another HGPS patient had uniparental disomy of 1q, involving the region flanked by markers D1S498 and D1S2836 (Eriksson et al. 2002), which harbours LMNA. Finally, there have been direct suggestions that LMNA mutations underlie HGPS (http://grants.nih.gov/grants/ guide/pa-files/PA-03-069.html and Eriksson et al. 2003). Thus, LMNA is an excellent candidate gene for HGPS.

The Wiedemann-Rautenstrauch syndrome (WRS; MIM 264090) is another extremely rare phenotype that is characterized by progeroid features from birth (Rautenstrauch et al. 1977; Wiedemann 1979). This is associated with a spectrum of clinical features, including delayed psychomotor development and physical growth, alopecia, macrocephaly and lipoatrophy (Arboleda et al. 1997; Bitoun et al. 1995; Castineyra et al. 1992; Devos et al. 1981; Martin et al. 1984; Pivnick et al. 2000; 
Toriello 1990). No genomic DNA mutations have yet been reported in WRS, but because lipodystrophy is a central feature, genes that cause lipodystrophy can be considered as candidates. Based on these lines of evidence, we sequenced $L M N A$ from genomic DNA of cell lines from HGPS and WRS patients.

\section{Materials and methods}

Study subjects

Genomic DNAs from HGPS probands NG07091, NG03506, NG03259, NG03344, NG10579, NG10587 and NG10801, and the fibroblast cell lines from WRS probands AG09233 and AG13207 were obtained from the Coriell Cell Repositories (Camden, N.J.). The clinical attributes of the HGPS and WRS probands were described in detail on the Coriell Cell Repository website (http:// locus.umdnj.edu/ccr/) and the key attributes are summarized in Table 1. All HGPS and WRS probands studied were unrelated Caucasians. All samples had been deposited at the Coriell Cell Repositories between 1978 and 1990.

Mutation-containing exons were subsequently screened in samples from 100 clinically normal Caucasian subjects in order to determine whether any observed genomic variant was also present in the normal population. The University of Western Ontario Ethics Review Panel had approved the study.

\section{Screening $L M N A$ for DNA variants}

Established methods were used to extract genomic DNA, then to amplify genomic DNA and to directly sequence the $L M N A$ coding sequence and promoter (Cao and Hegele 2000). Mutations were identified using Sequence Navigator software (PE-Applied Biosystems, Mississauga, Ont.).
Determining the phase of $L M N A$ mutations

in HGPS proband NG07091

Because two mutations were seen in the subject NG07091, subcloning was performed to separate the alleles in order to determine whether the mutations were in a cis or trans relationship. A 1,069bp fragment containing $L M N A$ exons $8-10$ was amplified from the genomic DNA of HGPS proband NG7091 using primers F-5'-GCAAGATACACCCAAGAGCC-3' and R-5'-ACACCTGGGTTCCCTGTTC- $3^{\prime}$. The amplified product was subcloned into the pCR2.1 vector (TA cloning kit; Invitrogen, Carlsbad, Calif.) and purified after EcoRI digestion of plasmid DNA. Five gelpurified plasmid inserts were each split into two aliquots. Because the R471C (c.1623C > T) predicted loss of an HhaI site and R527C (c. $1791 \mathrm{C}>\mathrm{T}$ ) predicted the loss of a BsiWI site, each aliquot was digested either with endonuclease $H h a \mathrm{I}$ or $B s i \mathrm{WI}$. Fragments after digestion were resolved on $2 \%$ agarose gels.

\section{Statistical analysis}

Fisher's exact test was used to compare allele frequencies between affected and normal subjects (SAS version 6.12, SAS Institute, Cary, N.C.).

\section{Results}

\section{Identification of $L M N A$ genomic DNA variants}

Results of the analysis of genomic DNA sequence of $L M N A$ in HGPS and WRS probands are shown in Table 1. We found that: (1) all seven genomes from HGPS probands had novel LMNA coding sequence variants; (2) neither genome from the WRS probands had a $L M N A$ sequence variation; (3) none of the 100 normal control genomes had any of these novel LMNA

Table 1 Clinical and molecular features of patients with Hutchinson-Gilford progeria (HGPS) and Wiedemann-Rautenstrauch progeroid (WRS) syndromes

\begin{tabular}{|c|c|c|c|c|}
\hline Disease & Identification & Age, sex and ethnicity & $L M N A$ sequence & Comments \\
\hline HGPS & NG03259 & 10 years, female Caucasian & $\begin{array}{l}\text { Simple heterozygote } \\
\text { exon } 11 \text { c. } 2036 \mathrm{C}>\mathrm{T}\end{array}$ & $\begin{array}{l}\text { Typical phenotype, mild type } \\
2 \text { diabetes }\end{array}$ \\
\hline HGPS & NG03344 & 10 years, male Caucasian & $\begin{array}{l}\text { Simple heterozygote } \\
\text { exon } 11 \text { c. } 2036 \mathrm{C}>\mathrm{T}\end{array}$ & Typical phenotype, scleroderma \\
\hline HGPS & NG03506 & 13 years, male Caucasian & $\begin{array}{l}\text { Simple heterozygote } \\
\text { exon } 11 \text { c. } 2036 \mathrm{C}>\mathrm{T}\end{array}$ & Typical phenotype \\
\hline HGPS & NG07091 & 28 years, female Caucasian & $\begin{array}{l}\text { Compound heterozygote } \\
\text { - exon } 8, \text { c. } 1623 \mathrm{C}>\mathrm{T} \text {, } \\
\text { R471C } \\
\text { - exon } 9, \text { c. } 1791 \mathrm{C}>\mathrm{T} \text {, } \\
\text { R527C }\end{array}$ & Apparently typical phenotype \\
\hline HGPS & NG10579 & 5 years, male Caucasian & $\begin{array}{l}\text { Simple heterozygote } \\
\text { exon } 11 \text { c. } 2036 \mathrm{C}>\mathrm{T}\end{array}$ & Typical phenotype \\
\hline HGPS & NG10587 & 9 years, male Caucasian & $\begin{array}{l}\text { Simple heterozygote } \\
\text { exon } 11 \text { c. } 2036 \mathrm{C}>\mathrm{T}\end{array}$ & Typical phenotype, arthritis, angina \\
\hline HGPS & NG10801 & 6 years, female Caucasian & $\begin{array}{l}\text { Simple heterozygote } \\
\text { exon } 11 \text { c. } 2034 \mathrm{G}>\mathrm{A} \text {, } \\
\text { G608S }\end{array}$ & $\begin{array}{l}\text { Typical phenotype, mandibular } \\
\text { hypoplasia }\end{array}$ \\
\hline WRS & AG09233 & 8 months, male Caucasian & No mutations & $\begin{array}{l}\text { Severe lipodystrophy, increased ventricle } \\
\text { size, poor weight gain, macrocephaly, } \\
\text { blue sclerae no teeth, alopecia }\end{array}$ \\
\hline WRS & AG13207 & 1 month, male Caucasian & No mutations & $\begin{array}{l}\text { Macrocephaly, sparse scalp hair, } \\
\text { smallfacies, low-set ears, hypotonia, } \\
\text { lipodystrophy, micrognathia, club feet }\end{array}$ \\
\hline
\end{tabular}


variants. The finding that each HGPS proband had at least one of these rare $L M N A$ mutations indicates a strong, non-random association between the disease and the mutations $\left(P<4 \times 10^{-11}\right.$, Fisher's exact test $)$. One HGPS proband (NG10801) was a simple heterozygote for a novel missense mutation in exon 11, namely G608S (c.2034G >A). Five HGPS probands were simple heterozygotes for a novel synonymous mutation in exon 11 , namely c.2036C $>\mathrm{T}$.

In order to determine whether mutations R471C and R527C in HGPS proband NG07091 were in a cis or trans relationship, the genomic region spanning $L M N A$ exons 8-10 was amplified and then subcloned. Aliquots of five plasmid inserts were digested with HhaI: four had the expected fragment sizes of $585,245,97,91,39$ and $12 \mathrm{bp}$, while the fifth had fragment sizes of $585,245,188$, 39 and $12 \mathrm{bp}$, consistent with a lost HhaI site resulting from R471C (c.1623C $>$ T). Aliquots of these inserts were digested separately with $B s i \mathrm{WI}$ : the insert that showed the abnormal HhaI fragment pattern had the expected BsiWI fragment pattern of 721 and $348 \mathrm{bp}$, while the four fragments that showed the normal HhaI pattern had only a single 1,069-bp fragment, consistent with the loss of the BsiWI recognition site. This confirmed that HGPS proband NG07091 was a compound heterozygote for R471C and R527C missense mutations. Neither parental phenotype data nor DNA was available for further study.

\section{Discussion}

We report four novel and rare $L M N A$ coding sequence variants, namely R471C, R527C, G608S and c.2036C > T, which were detected by sequencing genomic DNA from seven unrelated HGPS probands. The genomes of all seven HGPS probands had a variant $L M N A$ sequence, while no genome of 100 normal control subjects had a rare $L M N A$ variant, indicating a strong non-random statistical association between $L M N A$ variation and HGPS $\left(P<4 \times 10^{-11}\right)$. In contrast, neither genome from the two WRS probands had any LMNA sequence abnormality. The findings support the idea that HGPS is associated with genomic DNA variation of $L M N A$, while WRS is not.

Two HGPS probands had missense mutations in $L M N A$. One of these probands, NG10801, a simple heterozygote for G608S, was a six-year-old female Caucasian with mandibular dysplasia in addition to the classic features of HGPS. The other proband, NG07091, a compound heterozygote for $\mathrm{R} 471 \mathrm{C}$ and $\mathrm{R} 527 \mathrm{C}$, was the oldest HGPS patient that we studied. While no DNA or clinical data from parents or family members could be analysed for this study, the findings from these two HGPS indicate that HGPS inheritance may be more complicated than classical Mendelian dominant or recessive patterns. This would be consistent with prior observations that some HGPS patients have specific cytogenetic abnormalities (Brown et al. 1990; Luengo et al. 2002) and uniparental disomy of 1q in some cases (Eriksson et al. 2002).

Since each parent of NG07091 had contributed one LMNA allele with a novel missense mutation, it would have been of interest to determine whether each also expressed any clinical features of a laminopathy. Unfortunately, this information was not readily available to us. In each of these two mutations, cysteine replaces wild-type arginine, which is a common type of substitution that is seen in other autosomal dominant laminopathies (Burke and Stewart 2002). At present, it cannot be determined whether milder laminopathies are seen in the heterozygous state for $\mathrm{R} 471 \mathrm{C}$ or $\mathrm{R} 527 \mathrm{C}$, with compound heterozygosity leading to the more severe phenotype of HGPS. Alternatively, one or both of these mutations may have no associated clinical phenotype, with progeria representing a true autosomal recessive trait.

Five HGPS probands were simple heterozygotes for the rare synonymous $L M N A$ c. $2036 \mathrm{C}>\mathrm{T}$ mutation in exon 11. The statistical significance of the absence of c. $2036 \mathrm{C}>\mathrm{T}$ from the genomes of 100 normal subjects $\left(P<10^{-8}\right.$, Fisher's exact test) strongly indicates mechanistic importance that is specific to HGPS. This importance is amplified when considering the complete absence of $L M N A$ c. $2036 \mathrm{C}>\mathrm{T}$ from the genomes of hundreds of other subjects that were sequenced during mutational screening for disease. While silent at the amino acid level, it would be important to consider the possibility that $L M N A$ c. $2036 \mathrm{C}>\mathrm{T}$ might have some other functional impact, such as an affect on RNA splicing, although functional studies to assess this possibility are beyond the scope of this preliminary report. An alternative explanation is that there might be linkage disequilibrium between c.2036C $>\mathrm{T}$ and another unmeasured LMNA mutation. However, this possibility is made somewhat less likely by our sequencing strategy, which captured $\sim 700 \mathrm{bp}$ of the LMNA promoter, $\sim 500$ bp of the LMNA $3^{\prime}$-untranslated region and $\sim 100$ bp of intronic sequence at each intron-exon boundary.

The distribution of the HGPS mutations in $L M N A$ suggests that lamin A, specifically, is the affected isoform in this disease (Burke and Stewart 2002). There are no previously reported mutations at $L M N A$ codons 471 and 608; however, R527P was found in a patient with autosomal dominant Emery-Dreifuss muscular dystrophy (Bonne et al. 1999). This indicates that different mutations at codon 527 are associated with different phenotypes. Furthermore, it seems an interesting coincidence that the nucleotide sequence of codon 608 is altered in both the G608S and c.2036C $>\mathrm{T}$ mutations. Codon 608 is specific to the lamin $\mathrm{A}$ isoform and the G608S and c.2036C $>\mathrm{T}$ mutations are among the most $3^{\prime}$ reported in $L M N A$. These two mutations have apparently been observed in other HGPS subjects (Eriksson et al. 2003).

The coexistence of lipodystrophy and progeroid features in WRS made $L M N A$ a reasonable candidate 
gene to have considered in this syndrome. Assuming no genetic heterogeneity, our findings suggest that LMNA mutations are not associated with WRS, although the number of WRS probands that we screened was admittedly small. However, WRS is even rarer than HGPS, so while obtaining more substantial numbers of subjects for additional genomic screening of $L M N A$ and other candidate genes would be desirable, it might be difficult.

In conclusion, our findings suggest that HGPS is a laminopathy, bringing to seven the number of inherited diseases that result from $L M N A$ mutations (Burke and Stewart 2002). The mechanism(s) by which the observed $L M N A$ mutations in HGPS might cause disease, like the $L M N A$ mutations in all laminopathies, is unclear. The $L M N A$ missense mutations might affect interactions with transcription factors that would determine the specific clinical outcomes (Burke and Stewart 2002). The exon 11 c.2036C $>$ T mutation might affect RNA splicing, but an in vitro assay of this function would be required to prove this. In contrast, the related WRS phenotype does not appear to be a laminopathy. The growing list and clinical relevance of laminopathies will hopefully intensify the efforts to understand how mutations in $L M N A$ lead to the specific clinical phenotypes.

Acknowledgements Dr. Hegele holds a Canada Research Chair (Tier I) in Human Genetics and a Career Investigator award from the Heart and Stroke Foundation of Ontario. This work was supported by grants from Canadian Institutes for Health Research (MT13430), the Canadian Genetic Diseases Network and the Blackburn Group.

\section{References}

Arboleda H, Quintero L, Yunis E (1997) Wiedemann-Rautenstrauch neonatal progeroid syndrome: report of three new patients. J Med Genet 34:433-437

Bitoun P, Lachassine E, Sellier N, Sauvion S, Gaudelus J (1995) The Wiedemann-Rautenstrauch neonatal progeroid syndrome: a case report and review of the literature. Clin Dysmorph $4: 239-245$

Bonne G, Raffaele di Barletta M, Varnous S, Becane HM, Hammouda EH, Merlini L, Muntoni F, Greenberg CR, Gary F, Urtizberea JA, Duboc D, Fardeau M, Toniolo D, Schwartz $\mathrm{K}$ (1999) Mutations in the gene encoding lamin A/C cause autosomal dominant Emery-Dreifuss muscular dystrophy. Nat Genet 21:285-288

Brown WT, Abdenur J, Goonewardena P, Alemzadeh R, Smith M, Friedman S, Cervantes C, Bandyopadhyay S, Zaslav A, Kunaporn S, Serotkin A, Lifshitz F (1990) Hutchinson-Gilford progeria syndrome: clinical, chromosomal and metabolic abnormalities (Abstract). Am J Hum Genet 47:A50

Burke B, Stewart CL (2002) Life at the edge: the nuclear envelope and human disease. Nat Rev Mol Cell Biol 3:575-585
Cao H, Hegele RA (2000) Nuclear lamin A/C R482Q mutation in canadian kindreds with Dunnigan-type familial partial lipodystrophy. Hum Mol Genet 9:109-112

Castineyra G, Panal M, Lopez Presas H, Goldschmidt E, Sanchez JM (1992) Two sibs with Wiedemann-Rautenstrauch syndrome: possibilities of prenatal diagnosis by ultrasound. J Med Genet 29:434-436

de Paula Rodrigues GH, das Eiras Tamega I, Duque G, Spinola Dias Neto V (2002) Severe bone changes in a case of Hutchinson-Gilford syndrome. Ann Genet 45:151-155

Devos EA, Leroy JG, Fryns JP, van den Berghe H (1981) The Wiedemann-Rautenstrauch or neonatal progeroid syndrome: report of a patient with consanguineous parents. Eur J Pediatr 136:245-248

Eriksson M, Singer J, Scott L, Dutra A, Boehnke M, Collins FS (2002) Uniparental isodisomy of chromosome 1q in a patient with Hutchinson-Gilford progeria syndrome (Abstract). Am J Hum Genet 71:A176

Eriksson M, Brown WT, Gordon LB, Glynn MW, Singer J, Scott L, Erdos MR, Robbins CM, Moses TY, Berglund P, Butra A, Pak E, Durkin S, Csoka AB, Boehnke M, Glover TW, Collins FS (2003) Recurrent de novo point mutations in lamin A cause Hutchinson-Gilford progeria syndrome. Nature (in press)

Gabr M, Hashem N, Hashem M, Fahmi A, Safouh M (1960) Progeria, a pathologic study. J Pediatr 57:70-77

Gilford H (1904) Ateleiosis and progeria: continuous youth and premature old age. Brit Med J 2:914-918

Hutchinson J (1886) Case of congenital absence of hair, with atrophic condition of the skin and its appendages, in a boy whose mother had been almost wholly bald from alopecia areata from the age of six. Lancet I:923

Luengo WD, Martinez AR, Lopez RO, Basalo CM, Rojas-Atencio A, Quintero M, Borjas L, Morales-Machin A, Ferrer SG, Bernal LP, Canizalez-Tarazona J, Pena J, Luengo JD, Hernandez JC, Chang JC (2002) Del(1)(q23) in a patient with Hutchinson-Gilford progeria. Am J Med Genet 113:298-301

Martin JJ, Ceuterick CM, Leroy JG, Devos EA, Roelens JG (1984) The Wiedemann-Rautenstrauch or neonatal progeroid syndrome: neuropathological study of a case. Neuropediatrics $15: 43-48$

Novelli G, Muchir A, Sangiuolo F, Helbling-Leclerc A, D’Apice MR, Massart C, Capon F, Sbraccia P, Federici M, Lauro R, Tudisco C, Pallotta R, Scarano G, Dallapiccola B, Merlini L, Bonne G (2002) Mandibuloacral dysplasia is caused by a mutation in $L M N A$ encoding lamin $\mathrm{A} / \mathrm{C}$. Am $\mathrm{J}$ Hum Genet $71: 426-431$

Parkash H, Sidhu SS, Raghavan R, Deshmukh RN (1990) Hutchinson-Gilford progeria: familial occurrence. Am J Med Genet 36:43

Paterson D (1922) Case of progeria. Proc Roy Soc Med 16:42

Pivnick EK, Angle B, Kaufman RA, Hall BD, Pitukcheewanont P, Hersh JH, Fowlkes JL, Sanders LP, O'Brien JM, Carroll GS, Gunther WM, Morrow HG, Burghen GA, Ward JC (2000) Neonatal progeroid (Wiedemann-Rautenstrauch) syndrome: report of five new cases and review. Am J Med Genet 90:131-140

Rautenstrauch T, Snigula F, Krieg T, Gay S, Muller PK (1977) Progeria: a cell culture study and clinical report of familial incidence. Eur J Pediatr 124:101-111

Toriello HV (1990) Wiedemann-Rautenstrauch syndrome. J Med Genet 27:256-257

Wiedemann HR (1979) An unidentified neonatal progeroid syndrome: follow-up report. Eur J Pediatr 130:65-70 